\title{
Demand and willingness to pay for different treatment and care services among patients with heart diseases in Hanoi, Vietnam
}

This article was published in the following Dove Press journal:

Patient Preference and Adherence

\begin{abstract}
Bach Xuan Tran, ${ }^{1,2}$ Giang Thu Vu, ${ }^{3}$ Thu Hong Thi Nguyen, ${ }^{4}$ Long Hoang Nguyen, ${ }^{5}$ Dat Dinh Pham, ${ }^{4}$ Viet Quang Truong, ${ }^{4}$ Thao Phuong Thi Thai, ${ }^{6}$ Thuc Minh Thi Vu, ${ }^{7}$ Tuan Quoc Nguyen, ${ }^{8}$ Vu Nguyen, ${ }^{9}$ Trang Huyen Thi Nguyen, ${ }^{10}$ Carl A Latkin, ${ }^{2}$ Cyrus SH Ho, " Roger CM Ho ${ }^{12}$
\end{abstract}

'Department of Health Economics, Institute for Preventive Medicine and Public Health, Hanoi Medical University, Hanoi, Vietnam; ${ }^{2}$ Department of Health, Behavior and Society, Bloomberg School of Public Health, Johns Hopkins University, Baltimore, MD, USA ${ }^{3}$ Center of Excellence in Evidencebased Medicine, Nguyen Tat Thanh University, Ho Chi Minh City, Vietnam; ${ }^{4}$ Hanoi Heart Hospital, Hanoi, Vietnam; ${ }^{5}$ Center of Excellence in Behavioral Medicine, Nguyen Tat Thanh University, Ho Chi Minh City, Vietnam; ${ }^{6}$ Department of General Planning and Department of Cardiology, Friendship Hospital, Hanoi, Vietnam; ${ }^{7}$ Tam Anh Hospital, Hanoi, Vietnam; ${ }^{8} \mathrm{Hanoi}$ Department of Health, Hanoi, Vietnam; 'Department of Neurosurgery Spine-Surgery, Hanoi Medical University Hospital, Hanoi, Vietnam; ${ }^{10}$ Institute for Global Health Innovations, Duy Tan University, Da Nang, Vietnam; "'Department of Psychological Medicine, National University Hospital, Singapore, Singapore; ${ }^{12}$ Department of Psychological Medicine, Yong Loo Lin School of Medicine, National University of Singapore, Singapore

Correspondence: Bach Xuan Tran Department of Health Economics, Institute for Preventive Medicine and Public Health, Hanoi Medical University, No.I Ton That Tung street, Dong Da district, Hanoi 100000 , Vietnam Tel +84982228662 Email bach.jhu@gmail.com
Introduction: In Vietnam, cardiovascular diseases (CVDs) are serious health issues, especially in the context of overload central heart hospitals, insufficient primary healthcare, and lack of customer-oriented care and treatment. Attempts to measure demand and willingness-to-pay (WTP) for different CVD treatments and care services have been limited. This study explored the preferences and WTP of patients with heart diseases for different home- and hospital-based services in Hanoi, Vietnam.

Methods: A cross-sectional survey was performed at the Hanoi Heart Hospital from July to December 2017. A contingent valuation was adopted to determine the preferences of patients and measure their WTP. Interval regressions were employed to determine the potential predictors of patients' WTP.

Results: Hospital-based services were most preferred by patients, with demand ranging from $45.6 \%$ to $82.3 \%$ of total participants, followed by home-based $(45.4 \%-45.8 \%)$ and administrative services (28.9\%-34\%). WTP for hospital-based services were in the range of US\$ 9.8 (US\$ 8.4-11.2)-US\$ 21.9 (US\$ 20.3-23.4), while figures for home-based and administrative services were US\$ 9.8 (US\$ 8.4-11.2)-US\$ 22 (US\$ 18.7-25.3) and 1.9 (US\$ 1.6-2.2)-US\$ 7.5 (US\$ 6.3-8.6), respectively. Patients who lived in urban areas, were employed, were having higher level of education, and were not covered by health insurance were willing to pay more for services, especially home-based ones.

Conclusion: Demand and WTP for home-based services among heart disease patients were moderately low compared with hospital-based ones. There is a need for more policies supporting home-based services, better communication of services' benefits to general public and patients, and introduction of services packages based on patients' preferences.

Keywords: willingness to pay, preference, heart disease, service, Vietnam

\section{Introduction}

Cardiovascular diseases (CVDs) have been well-documented as a global public health issue, resulting in more fatality globally than any other causes. ${ }^{1}$ A recent report estimated that, in 2015, 17.9 million cases of death were attributable to CVDs, accounting for about $30 \%$ of global deaths. ${ }^{2}$ Furthermore, CVDs have adverse health and economic impacts, such as substantial loss of healthy life-years as well as cost of treatments. For instance, it is estimated that inpatient cost of CVDs treatment can amount to at least US\$ 10,000 per patient. ${ }^{3-5}$ The economic burden placed on societies thus has been heavy - some European countries spent from $0.7 \%$ to $1.4 \%$ of their GDP to cover cost from CVDs; ${ }^{6}$ and this burden is even more so for low and middleincome countries. ${ }^{7}$ 
For alleviating the burden of CVDs, WHO has underlined the importance of health system's strengthening and the critical roles of primary health care in screening, managing, and controlling CVDs in the community. ${ }^{8}$ Home-based CVD care/intervention has been strongly promoted as a suitable solution for the task, as it would enable early disease detection, bypass long waiting time often experienced at hospitals and, eventually reduce clinical overload. There has been evidence supporting the cost-effectiveness of home-based care for CVDs. ${ }^{8}$ However, home-based services in many cases are not covered by health insurance. Thus, a co-payment mechanism, in which patients assume contributing to the cost, along with patients' willingness to pay (WTP) for the service should be investigated to assess the feasibility and acceptability of this model. A contingent valuation approach is often adopted to identify demand and WTP for different treatments and services among patients. ${ }^{9}$ Socio-economic characteristics of patients, ranging from age, gender, education to income level, and living location, have been found to influence their demand and WTP for health services. ${ }^{10,11}$

In Vietnam, CVD is one of the most common causes of death, with estimated 200,000 fatal cases annually. Despite growing prevalence and burden of CVDs, primary health care in Vietnam has still been inadequate in covering CVDs preventing and controlling needs. ${ }^{12}$ Major services have been provided by hospitals, leading to overcrowding and inefficient issues at these facilities, especially the central ones. ${ }^{13}$ Given the need of a comprehensive strategy for decreasing CVDs' burden, the Vietnam Government has issued a National Strategy Guideline to underline the importance of home-based and primary health care in preventing CVDs. ${ }^{14}$ However, although attempts have been made to study the prevalence and associated risk factors of heart disease in Vietnam, literature looking into preferences of patients for heart disease treatments and related health care services has been limited. Therefore, this study aims to explore the preferences and WTP of patients with heart disease for different home- and hospital-based services in Hanoi, Vietnam.

\section{Materials and methods \\ Study design and participants}

From July to December 2016, a cross-sectional survey was carried out at the Hanoi Heart Hospital. We invited both in- and outpatients who had examination and treatment in Hanoi Heart Hospital to enroll in the survey if they matched the following criteria: 1) having capacity to answer the questionnaire (ie, did not have severe physical or psychological impairments that could affect their responses),
2) using services at the hospital, and 3) accepting to take part in this study and gave written informed consent. The sample consisted of 600 patients (included 300 out-patients and 300 in-patients from 7 departments in Hanoi Heart Hospital) (response rate 100\%).

\section{Measures and instruments}

We conducted face-to-face interview using a structured questionnaire. The data collection team included well-trained students at Hanoi Medical University. We collected data on socio-demographic characteristics (gender, age, occupation, and education), types of patient (in- or outpatients), number of times visiting hospitals in the last 12 months for using health services, whether having health insurance or not, and WTP for different care and treatment services.

\section{Preference and WTP for different care and treatment services}

Prior to assessing the WTP of patients through a series of questions, we provided them with the information regarding 1) the current situation of health diseases in Vietnam, 2) the key effects of different care and treatment services, and 3) the co-payment mechanism for these services. We also asked the patients to assume that these packages would not be covered by any financial aids in order to assure that no bias occurred when evaluating patients' WTP. We then employed a contingent valuation approach using double-bounded dichotomous choice (DBDC) questions backed by an openended (OE) question to measure the WTP of patients. DBDC approach allowed for more refined information regarding the WTP of patients compared with single-bounded format where only a single question was asked and has also been claimed to be more efficient in estimating WTP. ${ }^{15,16}$ The addition of OE question would reduce bias and inaccuracy of estimation introduced by the pre-determined price embedded in each bid. ${ }^{17}$

We investigated the price of these services of interests in several public and private hospitals that delivered similar services in order to identify the starting bids. The list of services and bids for measurement are described in Table 1 .

A maximum of 4 questions were asked to patients. Initially, participants were asked to answer the question: "Would you be willing to pay for (name of service)?". This question was also used to determine the demand for service of participants, in essence, demand meant their WTP for any service mentioned in Table 1. If "yes", they were then asked: "Would you be willing to pay for this service if the price were (Bid 1)?", and doubled the bid (Bid 2 and Bid 3) for 
Table I List of services and bids (unit: US\$)

\begin{tabular}{|c|c|c|c|c|c|}
\hline Services & Bid I & Bid 2 & Bid 3 & Bid 4 & Bid 5 \\
\hline \multicolumn{6}{|l|}{ Administrative } \\
\hline Selecting preferred physicians & 22.0 & 44.1 & 88.1 & 11.0 & 5.5 \\
\hline Schedule appointments (during work hours) & 4.4 & 8.8 & 17.6 & 2.2 & I.I \\
\hline Schedule appointments (out-of-work hours) & 22.0 & 44.1 & 88.1 & 11.0 & 5.5 \\
\hline \multicolumn{6}{|l|}{ Hospital-based } \\
\hline Pick up to the hospital by hospital cars and staff for examination & 22.0 & 44. 1 & 88.1 & II.0 & 5.5 \\
\hline Perform examination, ultrasound, ECG, and INR after CVD intervention/surgery at the hospital & 26.4 & 52.9 & 105.7 & 13.2 & 6.6 \\
\hline Perform examination, ultrasound, and ECG at the hospital to treat CVD & 23.8 & 47.6 & 95.2 & 11.9 & 5.9 \\
\hline Perform examination, ultrasound, and ECG at the hospital to manage, consult, and prevent & 23.8 & 47.6 & 95.2 & 11.9 & 5.9 \\
\hline \multicolumn{6}{|l|}{ CVD and other-related diseases } \\
\hline \multicolumn{6}{|l|}{ Home-based } \\
\hline General examination at home & 22.0 & 44.1 & 88.1 & II.0 & 5.5 \\
\hline $\begin{array}{l}\text { Perform examination, ultrasound, ECG, and INR after CVD intervention/surgery at home } \\
\text { (with one physician and one nurse) }\end{array}$ & 61.7 & 123.3 & 246.7 & 30.8 & 15.4 \\
\hline Perform examination, ultrasound, and ECG at home to CVD (with I physician and I nurse) & 57.3 & 114.5 & 229.1 & 28.6 & 14.3 \\
\hline $\begin{array}{l}\text { Perform examination, ultrasound, and ECG at home to manage, consult, and prevent CVD } \\
\text { and other-related diseases (with I physician and I nurse) }\end{array}$ & 61.7 & 123.3 & 246.7 & 30.8 & 15.4 \\
\hline
\end{tabular}

Note: Exchange rate 22,700 VND = US\$ I.

Abbreviations: CVD, cardiovascular disease; ECG, Electrocardiography; INR, international normalized ratio - for testing prothrombin time.

answer "Yes" or halved the bid (Bid 4 and Bid 5) for answer "No". Finally, patients were asked: "What is the maximum price you would be willing to pay for (name of service)?" The process is summarized in Figure 1.

\section{Statistical analysis}

Stata version 13.0 (Stata Corp. LP, College Station, TX, USA) was used to analyze the data. Socio-economic status and the demands for different care and treatment packages were described, and chi-squared test was used to determine the differences in these characteristics by living location (urban and rural). $P$-value $<0.05$ was considered to be statistically significant. Interval regression was used to compute the amount of WTP for different packages of care and treatment, and also to identify the associations between the socio-economic status, (age, gender, occupation, and education), the health insurance status, the type of patients (in- or outpatient), and the number of times visiting the hospital in the last 12 months. Stepwise backward strategies were used, with $P<0.2$ being the threshold used to build reduced models.

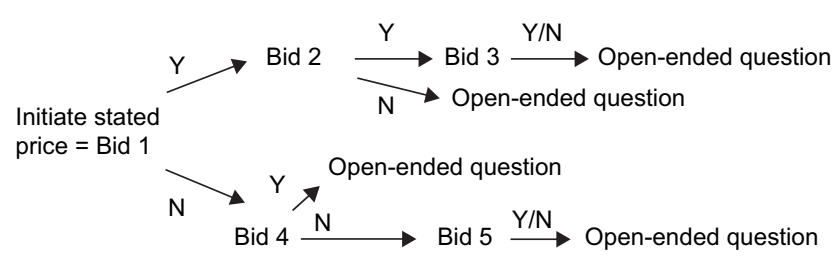

Figure I The bidding process.

Notes: N: No/unwillingness to pay; Y: Yes/willingness to pay.

\section{Ethics approval}

Proposal of this study was approved by the Institutional Review Board of Hanoi Medical University.

\section{Results}

Of the 600 patients interviewed, majority were female (58.5\%), being $>60$ years old $(53.7 \%)$ and covered by health insurance $(82.7 \%)$. Blue-collar was the most popular occupation among participants, accounted for $38.8 \%$, followed by unspecified occupation (30\%). Only $34.4 \%$ of interviewees had high school and above level of education, while $8.5 \%$ were illiterate. Comparing patients' demographic characteristics by their residency, ie, urban versus rural, similar patterns were found regarding gender, age group, and health insurance coverage. Differences were found regarding occupation and education: the most popular occupation of urban respondents was found to be unspecified jobs (37.9\%), while for rural group, it was blue-collar jobs (52.5\%); 50.5\% of urban residents had at least high school education, while the figure for rural residents was $20.3 \%$. The proportion of in- and outpatients was quite balanced between urban and rural groups (50.4\% and 49.6\% vs $49.7 \%$ and $50.3 \%$, respectively) (Table 2 ).

The demand for administrative services ranged from $28.9 \%$ of total respondents for out-of-work hours schedule appointments to $34 \%$ for selecting preferred physicians, with demand from urban citizens significantly higher than that of rural residents. Hospital-based services were the most demanded services compared with administrative and home-based services, with demand ranging from $45.6 \%$ to 
Table 2 Demographics of respondents

\begin{tabular}{|c|c|c|c|c|c|c|c|}
\hline \multirow[t]{2}{*}{ Characteristics } & \multicolumn{2}{|c|}{ Urban } & \multicolumn{2}{|c|}{ Rural } & \multicolumn{2}{|c|}{ Total } & \multirow[t]{2}{*}{$P$-value } \\
\hline & $\mathbf{N}$ & $\%$ & $\mathbf{N}$ & $\%$ & $\mathbf{N}$ & $\%$ & \\
\hline \multicolumn{8}{|l|}{ Gender } \\
\hline Male & 115 & $4 I .1$ & 134 & 41.9 & 249 & 41.5 & 0.84 \\
\hline Female & 165 & 58.9 & 186 & 58.1 & 351 & 58.5 & \\
\hline \multicolumn{8}{|c|}{ Age group, years } \\
\hline$<30$ & 22 & 7.9 & 34 & 10.6 & 56 & 9.3 & 0.20 \\
\hline $30-<45$ & 24 & 8.6 & 31 & 9.7 & 55 & 9.2 & \\
\hline $45-<60$ & 71 & 25.4 & 96 & 30.0 & 167 & 27.8 & \\
\hline$>60$ & 163 & 58.2 & 159 & 49.7 & 322 & 53.7 & \\
\hline \multicolumn{8}{|l|}{ Occupation } \\
\hline Unemployment & 35 & 12.5 & 35 & 10.9 & 70 & 11.7 & $<0.01$ \\
\hline Freelancer & 23 & 8.2 & 14 & 4.4 & 37 & 6.2 & \\
\hline White-collar ${ }^{\mathrm{a}}$ & 46 & 16.4 & 18 & 5.6 & 64 & 10.7 & \\
\hline Blue-collar ${ }^{\mathrm{b}}$ & 65 & 23.2 & 168 & 52.5 & 233 & 38.8 & \\
\hline Student & 5 & 1.8 & 11 & 3.4 & 16 & 2.7 & \\
\hline Others & 106 & 37.9 & 74 & 23.1 & 180 & 30.0 & \\
\hline \multicolumn{8}{|l|}{ Education } \\
\hline Illiterate & 19 & 6.8 & 32 & 10.0 & 51 & 8.5 & $<0.01$ \\
\hline Primary school & 38 & 13.6 & 76 & 23.8 & 114 & 19.0 & \\
\hline Secondary school & 81 & 28.9 & 147 & 45.9 & 228 & 38.0 & \\
\hline High school & 64 & 22.9 & 46 & 14.4 & 110 & 18.3 & \\
\hline College & 30 & 10.7 & 8 & 2.5 & 38 & 6.3 & \\
\hline University & 45 & 16.1 & 11 & 3.4 & 56 & 9.3 & \\
\hline Postgraduate & 3 & I.I & 0 & 0.0 & 3 & 0.5 & \\
\hline \multicolumn{8}{|c|}{ Having health insurance } \\
\hline Yes & 231 & 82.5 & 265 & 82.8 & 496 & 82.7 & 0.92 \\
\hline No & 49 & 17.5 & 55 & 17.2 & 104 & 17.3 & \\
\hline \multicolumn{8}{|c|}{ Type of patients } \\
\hline Outpatient & $|4|$ & 50.4 & 159 & 49.7 & 300 & 50.0 & 0.87 \\
\hline Inpatient & 139 & 49.6 & 161 & 50.3 & 300 & 50.0 & \\
\hline Total & 280 & 46.7 & 320 & 53.3 & 600 & 100.0 & \\
\hline
\end{tabular}

Notes: ${ }^{a}$ White collar: office or administrative jobs. ${ }^{\text {bBlue collar: manual, labor- }}$ intensive jobs.
$82.3 \%$ of total participants. Performance of examination, ultrasound, and ECG at the hospital to treat CVD and manage, consult, and prevent CVD and other related-diseases were the services with highest demand from patients (both at $82.3 \%$ ); those from rural areas had slightly higher demand than those from urban residents. From $45.4 \%$ to $45.8 \%$ of total respondents demand for home-based services: demand from urban citizens was significantly higher than that from rural counterparts (Table 3).

The WTP of respondents for administrative services ranged from an average of US\$ 1.9 (US\$ 1.6-2.2) for scheduling work-hour appointments to US\$ 7.5 (US\$ 6.3-8.6) for selecting preferred physicians. In general, urban residents were willing to pay more for services than rural residents. WTP for hospital-based service of picking up by hospital cars and staff was US\$ 9.8 (US\$ 8.4-11.2) on average, while WTP for services involving performance of examination, ultrasound, and ECG ranged from US\$ 19.5 (US\$ 17.7-21.3) to US\$ 21.9 (US\$ 20.3-23.4), relatively close to the price offered at Bid 1 (US\$ 26.4-23.8). On the other hand, WTP for home-based services involving performance of examination, ultrasound, and ECG was much lower than price of these services, ranging from an average of US\$ 20.9 (US\$ 17.6-24.2) to US\$22.9 (US\$ 19.6-26.2) versus bids of US\$ 57.3-61.7. WTP for general examination at home was, on average, US\$ 9.8 (US\$ 8.4-11.2) (Table 4).

Being in the age group of $>60$ years old and the number of times visiting the hospital last year were the factors that

Table 3 Demand for different services among patients

\begin{tabular}{|c|c|c|c|c|c|c|c|}
\hline \multirow[t]{2}{*}{ Services } & \multicolumn{2}{|c|}{ Urban } & \multicolumn{2}{|c|}{ Rural } & \multicolumn{2}{|c|}{ Total } & \multirow[t]{2}{*}{ P-value } \\
\hline & $\mathbf{N}$ & $\%$ & $\mathbf{N}$ & $\%$ & $\mathbf{N}$ & $\%$ & \\
\hline \multicolumn{8}{|l|}{ Administrative } \\
\hline Selecting preferred physicians $(n=547)$ & 108 & 42.0 & 78 & 26.9 & 186 & 34.0 & $P<0.01$ \\
\hline Schedule appointments (during work hours) $(n=544)$ & 107 & 41.8 & 69 & 24.0 & 176 & 32.4 & $P<0.01$ \\
\hline Schedule appointments (out-of-work hours) $(n=544)$ & 96 & 37.5 & 61 & 21.2 & 157 & 28.9 & $P<0.01$ \\
\hline \multicolumn{8}{|l|}{ Hospital-based service } \\
\hline Pick up to the hospital by hospital cars and staff for examination $(n=543)$ & 142 & 55.5 & 107 & 37.2 & 249 & 45.9 & $P<0.01$ \\
\hline $\begin{array}{l}\text { Perform examination, ultrasound, ECG, and INR after CVD intervention/surgery at the } \\
\text { hospital }(n=544)\end{array}$ & 164 & 64.1 & 187 & 64.9 & 351 & 64.5 & 0.83 \\
\hline Perform examination, ultrasound, and ECG at the hospital to treat CVD ( $n=543)$ & 216 & 84.4 & 231 & 80.5 & 447 & 82.3 & 0.24 \\
\hline Perform examination, ultrasound, and ECG at the hospital to manage, consult, and prevent & 216 & 84.4 & 231 & 80.5 & 447 & 82.3 & 0.24 \\
\hline \multicolumn{8}{|l|}{ CVD and other-related diseases $(n=543)$} \\
\hline \multicolumn{8}{|l|}{ Home-based services } \\
\hline General examination at home $(n=544)$ & 142 & 55.5 & 106 & 36.8 & 248 & 45.6 & $P<0.01$ \\
\hline $\begin{array}{l}\text { Perform examination, ultrasound, ECG, and INR after CVD intervention/surgery at home (with one } \\
\text { physician and one nurse) }(n=542)\end{array}$ & 114 & 44.5 & 96 & 33.6 & 210 & 38.8 & 0.01 \\
\hline Perform examination, ultrasound, and ECG at home to CVD (with I physician and I nurse) (n=542) & 136 & 53.1 & 112 & 39.2 & 248 & 45.8 & $P<0.01$ \\
\hline $\begin{array}{l}\text { Perform examination, ultrasound, and ECG at home to manage, consult, and prevent CVD and } \\
\text { other-related diseases (with I physician and I nurse) }(n=542)\end{array}$ & 136 & 53.1 & 110 & 38.5 & 246 & 45.4 & $P<0.01$ \\
\hline
\end{tabular}

Abbreviations: CVD, cardiovascular disease; ECG, electrocardiography; INR, international normalized ratio - for testing prothrombin time. 
Table 4 Amount of willingness to pay for different services of patient with CVD (unit: US\$)

\begin{tabular}{|c|c|c|c|c|c|c|}
\hline \multirow[t]{2}{*}{ Components of package } & \multicolumn{2}{|l|}{ Urban } & \multicolumn{2}{|l|}{ Rural } & \multicolumn{2}{|l|}{ Total } \\
\hline & Mean & $95 \% \mathrm{Cl}$ & Mean & $95 \% \mathrm{Cl}$ & Mean & $95 \% \mathrm{Cl}$ \\
\hline \multicolumn{7}{|l|}{ Administrative } \\
\hline Selecting preferred physicians $(n=\mid 86)$ & 8.8 & 7.2 to 10.4 & 6.3 & 4.8 to 7.8 & 7.5 & 6.3 to 8.6 \\
\hline Schedule appointments (during work hours) $(n=176)$ & 2.4 & 1.9 to 0.4 & 1.5 & 7.8 to 1.9 & 1.9 & 1.6 to 2.2 \\
\hline Schedule appointments (out-of-work hours) $(n=157)$ & 5.6 & 4.3 to 6.8 & 4.1 & 2.8 to 5.4 & 4.8 & 3.9 to 5.7 \\
\hline \multicolumn{7}{|l|}{ Hospital-based service } \\
\hline Pick up to the hospital by hospital cars and staff for examination $(n=248)$ & 11.4 & 9.3 to 13.5 & 8.5 & 6.6 to 10.4 & 9.8 & 8.4 to 11.2 \\
\hline $\begin{array}{l}\text { Perform examination, ultrasound, ECG, and INR after CVD intervention/surgery } \\
\text { at the hospital }(n=35 I)\end{array}$ & 19.6 & 16.9 to 22.4 & 19.4 & 17.0 to 21.8 & 19.5 & 17.7 to 21.3 \\
\hline Perform examination, ultrasound, and ECG at the hospital to treat CVD $(n=447)$ & 23.0 & 20.6 to 25.3 & 20.9 & 18.9 to 23.0 & 21.9 & 20.3 to 23.4 \\
\hline $\begin{array}{l}\text { Perform examination, ultrasound, and ECG at the hospital to manage, consult } \\
\text { and prevent CVD and other-related diseases }(n=447)\end{array}$ & 22.2 & 20.1 to 24.3 & 20.3 & 18.5 to 22.2 & 21.2 & 19.8 to 22.6 \\
\hline \multicolumn{7}{|l|}{ Home-based service } \\
\hline General examination at home $(n=248)$ & 12.6 & 10.4 to 2.2 & 7.5 & 5.7 to 9.2 & 9.8 & 8.4 to 11.2 \\
\hline $\begin{array}{l}\text { Perform examination, ultrasound, ECG, and INR after CVD intervention/surgery } \\
\text { at home (with one physician and one nurse) }(n=2 \mid 0)\end{array}$ & 23.0 & 18.2 to 27.8 & 19.1 & 14.5 to 23.7 & 20.9 & 17.6 to 24.2 \\
\hline $\begin{array}{l}\text { Perform examination, ultrasound, and ECG at home to CVD (with one physician } \\
\text { and one nurse) }(n=248)\end{array}$ & 24.4 & 19.6 to 29.1 & 19.9 & I5.4 to 24.4 & 22.0 & 18.7 to 25.2 \\
\hline $\begin{array}{l}\text { Perform examination, ultrasound, and ECG at home to manage, consult, and } \\
\text { prevent CVD and other-related diseases (with I physician and I nurse) }(n=246)\end{array}$ & 25.6 & 20.8 to 30.4 & 20.5 & 2.4 to 25.0 & 22.9 & 19.6 to 26.2 \\
\hline
\end{tabular}

Note: $n$ : the number of participants said yes to the first question: "Would you be willing to pay for (name of service)?".

Abbreviations: CVD, cardiovascular disease; ECG, electrocardiography; INR, international normalized ratio - for testing prothrombin time.

have significantly negative correlation with WTP for selecting preferred physicians (Coef.: $-3.4,95 \%$ CI: -6.5 to -0.4 and Coef.: $-0.4,95 \%$ CI: -0.7 to -0.0 ). Meanwhile, working as freelancers, being blue-collar workers, or not having health insurance was associated with WTP significantly higher for all administrative services. Respondents with education level above high school were willing to pay significantly more for appointments scheduling services, while working white-collar jobs positively correlated with WTP for selecting preferred physicians. Patients living in rural areas were willing to pay significantly less for administrative services offered (Table 5).

Working as freelancers (Coef.: 15; 95\% CI: 6.1 to 24), being educated at high school or higher, and not having health insurance were the factors found to be positively correlated with WTP for picking up services. On the contrary, being white-collar or blue-collar was associated with lower WTP for services involving examination, ultrasound, and ECG at

Table 5 Associated factors with the amount of willingness to pay for different administrative services

\begin{tabular}{|c|c|c|c|c|c|c|}
\hline \multirow[t]{2}{*}{ Factors } & \multicolumn{2}{|c|}{$\begin{array}{l}\text { Selecting preferred } \\
\text { physicians }\end{array}$} & \multicolumn{2}{|c|}{$\begin{array}{l}\text { Schedule } \\
\text { appointments } \\
\text { (during work hours) }\end{array}$} & \multicolumn{2}{|c|}{$\begin{array}{l}\text { Schedule } \\
\text { appointments } \\
\text { (out-of-work hours) }\end{array}$} \\
\hline & Coef. & $95 \% \mathrm{Cl}$ & Coef. & $95 \% \mathrm{Cl}$ & Coef. & $95 \% \mathrm{Cl}$ \\
\hline \multicolumn{7}{|l|}{ Age group (vs $<30$ years) } \\
\hline - $\geq 60$ years & $-3.4^{* *}$ & -6.5 to -0.4 & & & & \\
\hline \multicolumn{7}{|l|}{ Occupation (vs unemployed) } \\
\hline - Freelancer & $14.1 * * *$ & 7.3 to 20.9 & $4.7 * * *$ & 2.9 to 6.6 & $12.8 * * *$ & 7.8 to 17.8 \\
\hline - White-collar & 8. $\left.\right|^{* * *}$ & 2.5 to 13.8 & 1.2 & -0.3 to 2.8 & & \\
\hline - Blue-collar & $5.6 * * *$ & 2.2 to 9.0 & $\mathrm{I} .7 * * *$ & 0.8 to 2.6 & $4.3 * * *$ & 1.7 to 6.8 \\
\hline \multicolumn{7}{|l|}{ Education (vs less than high school) } \\
\hline - High school & & & & & 2.3 & -0.7 to 5.4 \\
\hline - Above high school & 3.2 & -1.6 to 8.0 & $2.1 * * *$ & 0.8 to 3.4 & $8.5^{* * * *}$ & 5.0 to 12.0 \\
\hline Living location (rural vs urban) & $-4.4 * * *$ & -7.6 to -1.2 & $-1.2 * * *$ & -2.1 to -0.4 & -1.8 & -4.2 to 0.7 \\
\hline Having health insurance (No vs Yes) & $10.6 * * *$ & 6.4 to 14.8 & $2.8 * * *$ & 1.7 to 3.9 & $7.7 * * *$ & 4.6 to 10.8 \\
\hline Number of times visiting hospital in the last 12 months & $-0.4 * *$ & -0.7 to -0.0 & & & & \\
\hline Type of patient (inpatient vs outpatient) & & & & & 1.7 & -0.6 to 4.1 \\
\hline
\end{tabular}

Notes: $* * P<0.05 ; * * * P<0.01$. 
Table 6 Associated factors with the amount of willingness to pay for different hospital-based services

\begin{tabular}{|c|c|c|c|c|c|c|c|c|}
\hline & \multicolumn{2}{|c|}{$\begin{array}{l}\text { Pick up to the } \\
\text { hospital by hospital } \\
\text { cars and staff for } \\
\text { examination }\end{array}$} & \multicolumn{2}{|c|}{$\begin{array}{l}\text { Perform examination, } \\
\text { ultrasound, ECG, } \\
\text { and INR after CVD } \\
\text { intervention/surgery } \\
\text { at the hospital }\end{array}$} & \multicolumn{2}{|c|}{$\begin{array}{l}\text { Perform examination, } \\
\text { ultrasound, and ECG } \\
\text { at the hospital to treat } \\
\text { CVD }\end{array}$} & \multicolumn{2}{|c|}{$\begin{array}{l}\text { Perform examination, } \\
\text { ultrasound, and ECG } \\
\text { at the hospital to } \\
\text { manage, consult, and } \\
\text { prevent CVD and } \\
\text { other-related diseases }\end{array}$} \\
\hline & Coef. & $95 \% \mathrm{Cl}$ & Coef. & $95 \% \mathrm{Cl}$ & Coef. & $95 \% \mathrm{Cl}$ & Coef. & $95 \% \mathrm{Cl}$ \\
\hline \multicolumn{9}{|l|}{ Age group (vs $<30$ years) } \\
\hline - $45-<60$ years & 3.9 & -0.8 to 8.5 & & & & & & \\
\hline \multicolumn{9}{|l|}{ Occupation (vs unemployed) } \\
\hline - Freelancer & $15.0 * * *$ & 6.1 to 24.0 & $24.9 * * *$ & 7.9 to 41.8 & & & & \\
\hline - White-collar & & & & & $-26.2 * * *$ & -41.2 to -11.3 & $-23.3 * * *$ & -37.1 to -9.6 \\
\hline - Blue-collar & & & & & $-21.9 * * *$ & -32.2 to -11.7 & $-19.6 * * *$ & -29.0 to -10.2 \\
\hline - Student & & & & & -21.5 & -48.6 to 5.6 & -18.1 & -43.3 to 7.1 \\
\hline - Others & -3.9 & -8.5 to 0.8 & & & & & & \\
\hline \multicolumn{9}{|l|}{ Education (vs less than high school) } \\
\hline - High school & $9.0 * * *$ & 3.3 to 14.6 & & & & & & \\
\hline - Above high school & $11.1 * * *$ & 5.2 to 17.1 & & & & & & \\
\hline Living location (rural vs urban) & $-3.7^{*}$ & -7.9 to 0.6 & & & & & & \\
\hline Having health insurance (No vs Yes) & $12.4 * * *$ & 6.7 to 18.2 & & & & & & \\
\hline $\begin{array}{l}\text { Number of times visiting the hospital in } \\
\text { the last } 12 \text { months }\end{array}$ & & & & & & & $1 . I^{* *}$ & 0.1 to 2.0 \\
\hline Type of patient (inpatient vs outpatient) & $3.9^{*}$ & -0.3 to 8.1 & & & $-12.2 * *$ & -21.6 to -2.8 & & \\
\hline
\end{tabular}

Notes: $* P<0.1 ; * *<0.05 ; * * *<0.01$. All coefficients with $P<0.2$ are presented.

Abbreviations: CVD, cardiovascular disease; ECG, electrocardiography; INR, international normalized ratio - for testing prothrombin time; Coef, Coefficient.

the hospital. Freelancers also paid significantly higher for performing examination, ultrasound, ECG, and INR after CVD intervention/surgery at the hospital. Number of times visiting the hospital last year was significantly positively correlated with performance of examination to manage, consult, and prevent CVD, while the relation between using impatient service and performing examination to treat CVD was significantly negative (Table 6).

Living in rural area was found to be negatively related to WTP for general examination at home (Coef.: $-5.4,95 \% \mathrm{CI}$ : -9.5 to -1.2$)$. In contrast, being freelancers and not having health insurance were the factors that had significantly positive correlation with WTP for all home-based services. Having above high school level of education and being admitted as inpatients induced significantly more WTP for all home-based services except those involving after CVD intervention. WTP for home-based services after CVD was significantly positively affected by occupation factor of working as white-collar or blue-collar workers (Table 7).

\section{Discussion}

This study has found that the demand and WTP for treatment and care services among heart disease patients were still relatively low, especially with regard to administrative and homebased services. Some patients' characteristics were found to be associated with these demands and WTP for different services, implying several potential solutions to address the overload of specialized hospitals in urban setting.

In this study, the demand for administrative and homebased services was generally low among respondents (roughly 34\% and 45\%, respectively). This was comparable with a study among Australian patients with chronic heart failure, which reported only $47.3 \%$ of participants preferring home-based services. ${ }^{10}$ Such difference can be explained partly by the general belief of patients with CVD that staying in the hospital would guarantee proper response of medical force should adverse symptoms be exhibited, whereas staying at home would not. Such belief has been further fortified by the lack of information provided for patients regarding home-based services' components and capability. In addition, current health insurance policy does not cover home-based services, meaning the patients would have to suffer normally high cost of CVD treatment without financial support, which, in turn, lead to patients' being reluctant to use the services.

The study has shown that the prices patients willing to pay for services were in general lower than the amount currently charged or expected to charge for these services, especially for home-based ones. Compared with the annual income of general Vietnamese population (2016 prices), the amount patients were willing to pay for home-based CVD health care accounted for roughly $1.3 \%-1.4 \%$, while the bid offered amounted to over $3.5 \%{ }^{18,19}$ The differences in bid-accepted 
Table 7 Associated factors with the amount of willingness to pay for different home-based services

\begin{tabular}{|c|c|c|c|c|c|c|c|c|}
\hline & \multicolumn{2}{|c|}{$\begin{array}{l}\text { General } \\
\text { examination at } \\
\text { home }\end{array}$} & \multicolumn{2}{|c|}{$\begin{array}{l}\text { Perform examination, } \\
\text { ultrasound, ECG, } \\
\text { and INR after CVD } \\
\text { intervention/surgery } \\
\text { at home }\end{array}$} & \multicolumn{2}{|c|}{$\begin{array}{l}\text { Perform examination, } \\
\text { ultrasound, and ECG } \\
\text { at home to CVD } \\
\text { (with I physician and } \\
\text { I nurse) }\end{array}$} & \multicolumn{2}{|c|}{$\begin{array}{l}\text { Perform examination } \\
\text { ultrasound, and ECG } \\
\text { at home to manage, } \\
\text { consult, and prevent } \\
\text { CVD and other- } \\
\text { related diseases }\end{array}$} \\
\hline & Coef. & $95 \% \mathrm{Cl}$ & Coef. & $95 \% \mathrm{Cl}$ & Coef. & $95 \% \mathrm{Cl}$ & Coef. & $95 \% \mathrm{Cl}$ \\
\hline \multicolumn{9}{|l|}{ Age group (vs < 30 years) } \\
\hline - $45-<60$ years & $6.8 * * *$ & 2.3 to 11.3 & & & 6.9 & -3.9 to 17.7 & 5.9 & -5.1 to 16. \\
\hline - $\geq 60$ years & & & -6.0 & -15.0 to 3.0 & & & & \\
\hline \multicolumn{9}{|l|}{ Occupation (vs unemployed) } \\
\hline - Freelancer & $20.8 * * *$ & I2.I to 29.6 & $55.8 * * *$ & 35.6 to 76.0 & $53.0 * * *$ & 32.0 to 73.9 & $41.2^{* * *}$ & 20.0 to 62.3 \\
\hline - White-collar & 4.9 & -2.5 to 12.3 & $16.6 * *$ & 0.0 to 33.1 & & & & \\
\hline - Blue-collar & & & $10.9 * *$ & 0.8 to 20.9 & $10.2^{*}$ & -0.5 to 21.0 & $10.6 *$ & -0.5 to 21 \\
\hline \multicolumn{9}{|l|}{ Education (vs less than high school) } \\
\hline - High school & 4.5 & -0.9 to 9.9 & & & $10.9 *$ & -2.0 to 23.7 & $11.9 *$ & -1.2 to 25. \\
\hline - Above high school & $7.4^{* *}$ & 1.0 to 13.9 & 9.8 & -4.1 to 23.7 & $20.8^{* * *}$ & 6.7 to 34.9 & $17.1^{* *}$ & 2.6 to 31.5 \\
\hline Living location (rural vs urban) & $-5.4^{* *}$ & -9.5 to -1.2 & -7.0 & -16.4 to 2.4 & $-8.4^{*}$ & -18.4 to 1.5 & $-10.1 *$ & -20.3 to 0.1 \\
\hline Having health insurance (No vs Yes) & $10.1 * * *$ & 4.4 to 15.7 & $18.3^{* * * *}$ & 6.5 to 30.2 & $22.2^{* * *}$ & 9.1 to 35.3 & $23.7^{* * *}$ & 10.4 to 37.1 \\
\hline Type of patient (inpatient vs outpatient) & $4.2 * *$ & 0.0 to 8.3 & & & $10.1^{* *}$ & 0.5 to 19.8 & $11.4^{* *}$ & 1.5 to 21.3 \\
\hline
\end{tabular}

Notes: $* P<0.1 ; * *<0.05 ; * * * 0.01$. All coefficients with $P<0.2$ are presented.

Abbreviations: CVD, cardiovascular disease; ECG, electrocardiography; INR, international normalized ratio - for testing prothrombin time; Coef, Coefficient.

prices may as well be the result of aforementioned lack of knowledge regarding the components and benefits of homebased services; in other words, patients may incorrectly consider these services to be basic and inefficient and thus should not cost too much, compared with those offered at the hospital. On the other hand, the WTP for hospital-based services was mostly at the same level as the price service providers were expected to charge (representing about 1.3\% of annual income), which partly reflects the faith of patients in the facilities and expertise of hospital staff as well as their familiarity with the capability and price of such services. ${ }^{18,19}$ This is somewhat different to the finding of a study on Taiwanese lung cancer patients, which showed that patients in general would be willing to pay less than offered price of treatments, even hospital-based ones. ${ }^{11}$ Author of that study claimed the reason for such behavior of patients to be the hardly affordable cost of cancer treatments. Ability to pay has indeed been found by many studies to be one of the significant influencing factors of WTP, along with residency area, ie, rural versus unban, among others. ${ }^{20}$ Our study made similar discovery, finding that higher WTP for services exhibited by urban residents, compared with their rural counterparts, which may be explained by urban citizens' general superior financial capability and awareness of the services' benefits.

The WTP of patients for services was also found to be influenced by education level, occupation, and whether in- or outpatient service was utilized. Highly educated patients, that is, those with high school or above level of education were willing to pay more for any kind of extra services, thanks to, perhaps, their accurate perception of the usefulness of these services. This was in line with previous studies that reported significant positive correlation between education level and WTP. ${ }^{21}$ Compared with the unemployed, those in the labor force were willing to pay more for administrative and home-based services, but, interestingly, less for hospitalbased ones, which may be explained, in parts, by the need of these working patients to save time waiting in crowded hospitals, as well as their ability to afford non-insured homebased services. Time and efforts saved by using home-based and administrative services may also be the reason for WTP more for these services by inpatient respondents, as they had experienced the burden associated with having to stay in the hospital. Finally, having no insurance is found to be significantly correlated with higher WTP for services; however, this may only indicate the determination of patients to pay to get the disease treated and not their financial capability.

This study has implications in both policy/management and clinical practices. It is recommended that policy makers put forward policies that facilitate home-based care encouraging hospitals to actively participate in providing home-based services, as well as expanding health insurance coverage to these services. This would assist the reduction of current overload at hospitals while enhancing the effectiveness of treatments and experience of patients. On the clinical level, hospitals should improve the quality of their hospital-based services to better cater to high demand from patients and, at the same time, seek to develop different service packages to suit varying patients' needs. In addition, 
communication on the characteristics and benefits of different CVD treatment services, especially home-based ones, should be made extensively to the patients as well as the community, such that better-informed, more efficient choices of services can be made.

This study also has some limitations. Since majority of the survey respondents were elderly with relatively low level of education, the response on demand and WTP for services may be biased by their lack of knowledge on prevailing services and prices as well as their dependence on family members for service payment. Second, we did not collect data on patients' income, which may be potentially associated with the WTP. Finally, the survey was conducted in just 1 hospital, albeit a large one, with regard to CVD; thus, it could only provide a part of the whole picture. Therefore, larger scale studies are called for to further examine the effectiveness of different health service packages.

\section{Conclusion}

In conclusion, demand and WTP for home-based services among heart disease patients were moderately low compared with hospital-based services. To increase the efficiency of services provided, reduce the heavy loads on heart hospitals, enhance the experiences of patients, and effectiveness of treatments, policy and clinical-level changes should be made to support the implementation of home-based and patients' preference-based services, while continuous efforts should be made to improve the general quality of hospital-based services and communication regarding heart disease treatments and services to the community.

\section{Author contributions}

Study conceptualization: BXT, GTV, THTN, LHN, DDP, VQT, TPTT, TMTV, TQN, VN, THN, CAL, CSHH, and RCMH. Methodology: BXT, GTV, THTN, and LHN. Study implementation: THTN, LHN, DDP, VQT, and TPTT. Data analysis: BXT, GTV, THTN, LHN, DDP, VQT, TPTT, TMTV, and TQN. Original draft preparation: BXT, GTV, THTN, LHN, DDP, VQT, TPTT, TMTV, TQN, VN, THN, CAL, CSHH, and RCMH. All authors reviewed the manuscript. All authors contributed toward data analysis, drafting and critically revising the paper and agree to be accountable for all aspects of the work.

\section{Disclosure}

The authors report no conflicts of interest in this work.

\section{References}

1. World Health Organization. Cardiovascular diseases (CVDs); 2017. Available from: http://www.who.int/en/news-room/fact-sheets/detail/ cardiovascular-diseases-(cvds). Accessed 1-6-2018.

2. Roth GA, Johnson C, Abajobir A, et al. Global, Regional, and National Burden of Cardiovascular Diseases for 10 Causes, 1990 to 2015. J Am Coll Cardiol. 2017;70(1):1-25.

3. Stewart S, Ekman I, Ekman T, Odén A, Rosengren A. Population impact of heart failure and the most common forms of cancer: a study of 1162 309 hospital cases in Sweden (1988 to 2004). Circ Cardiovasc Qual Outcomes. 2010;3(6):573-580.

4. Stewart S, Jenkins A, Buchan S, Mcguire A, Capewell S, Mcmurray JJ. The current cost of heart failure to the National Health Service in the UK. Eur J Heart Fail. 2002;4(3):361-371.

5. Brouwer ED, Watkins D, Olson Z, Goett J, Nugent R, Levin C. Provider costs for prevention and treatment of cardiovascular and related conditions in low- and middle-income countries: a systematic review. $B M C$ Public Health. 2015;15:1183.

6. Centre for Economics and Business Research. The Economic Cost of Cardiovascular Disease from 2014-2020 in Six European Economies. London: Centre for Economics and Business Research; 2014. Available from: https://www.sanita24.ilsole24ore.com/pdf2010/Sanita2/_Oggetti_Correlati/Documenti/Dibattiti-e-Idee/3Cebr\%20-\%20 The $\% 20$ economic $\% 20$ cost $\% 20$ of $\% 20$ cardiovascular $\% 20$ disease $\% 20$ from $\% 202014-2020 \% 20 \mathrm{in} \% 20$ six $\% 20$ European $\% 20$ economies. pdf?uuid=AbV1x4QK. Accessed September 3, 2018.

7. Gaziano TA. Reducing the growing burden of cardiovascular disease in the developing world: disease burden can be lowered with cost-effective interventions, especially by reducing the use of tobacco around the world. Health Affairs. 2007;26(1):13-24.

8. Inglis SC, Pearson S, Treen S, Gallasch T, Horowitz JD, Stewart S. Extending the horizon in chronic heart failure: effects of multidisciplinary, home-based intervention relative to usual care. Circulation. 2006; 114(23):2466-2473.

9. Yasunaga H, Ide H, Imamura T, Ohe K. Analysis of factors affecting willingness to pay for cardiovascular disease-related medical services. Int Heart J. 2006;47(2):273-286.

10. Whitty JA, Stewart S, Carrington MJ, et al. Patient preferences and willingness-to-pay for a home or clinic based program of chronic heart failure management: findings from the Which? trial. PLoS One. 2013; 8(3):e58347.

11. Lang HC. Willingness to pay for lung cancer treatment. Value Health. 2010;13(6):743-749.

12. van Minh H, do YK, Bautista MA, Tuan Anh T. Describing the primary care system capacity for the prevention and management of noncommunicable diseases in rural Vietnam. Int J Health Plann Manage. 2014;29(2):e159-e173.

13. Health VMo. Joint Annual Health Review 2014: Strengthening Prevention and Control of Non-Communicable Disease. Hanoi: Vietnam Ministry of Health; 2015. Available from: http://jahr.org.vn/downloads/ JAHR2014/JAHR\%202014_EN_full.pdf?phpMyAdmin=5b051 da883 f5a46f0982cec60527c597. Accessed September 3, 2018.

14. Government T. Decision No.376/QD-TTg dated March 20, 2015 on the national strategy on preventing non-communicable diseases for the 2015-2025 period. Hanoi, Vietnam: 2015. Available from: http://vncdc.gov.vn/vi/he-thong-van-ban/1/5/32/376qdttg. Accessed September 3, 2018.

15. Hanemann M, Loomis J, Kanninen B. Statistical Efficiency of DoubleBounded Dichotomous Choice Contingent Valuation. Am J Agric Econ. 1991;73(4):1255-1263.

16. Hanemann WM. Some Issues in Continuous- and Discrete-Response Contingent Valuation Studies. Northeastern J Agricult Resource Econ. 1985;14(1):5-13. 
17. Nguyen QL, Nguyen LH, Tran BX, et al. Co-financing for viral load monitoring during the course of antiretroviral therapy among patients with HIV/AIDS in Vietnam: a contingent valuation survey. PLoS One. 2017;12(2):e0172050.

18. General Statistics Office of Viet Nam. Monthly average income per capita at current prices by residence and by region by residence and region and year; 2016. Available from: http://www.gso.gov.vn/ default_en.aspx?tabid $=783$

19. Central VND-USD exchange rate as at $31 / 12 / 2016$. State Bank of Vietnam; 2016. Available from: https:/www.sbv.gov.vn/webcenter/por$\mathrm{tal} / \mathrm{vi} / \mathrm{menu} / \mathrm{rm} / \mathrm{tg} / \mathrm{tgbqlnh}$ ?_afrLoop=6965491497643000\#\%40\%3F_a frLoop\%3D6965491497643000\%26centerWidth\%3D80\%252 5\%26leftWidth\%3D20\%2525\%26rightWidth\%3D0\%2525\%2 6showFooter\%3Dfalse\%26showHeader\%3Dfalse\%26_adf.ctrlstate\%3Dcc3dih53f_184
20. Noor Aizuddin A, Sulong S, Aljunid S. Factors influencing willingness to pay for healthcare. BMC Public Health. 2012;12(Suppl 2):A37.

21. Chen F, Xu XL, Yang Z, Tan HW, Zhang L. The Willingness-to-Pay for General Practitioners in Contractual Service and Influencing Factors among Empty Nesters in Chongqing, China. Int J Environ Res Public Health. 2015;12(8):9330-9341.

\section{Publish your work in this journal}

Patient Preference and Adherence is an international, peer-reviewed, open access journal that focuses on the growing importance of patient preference and adherence throughout the therapeutic continuum. Patient satisfaction, acceptability, quality of life, compliance, persistence and their role in developing new therapeutic modalities and compounds to optimize clinical outcomes for existing disease states are major areas of interest for the journal. This journal has been accepted for indexing on PubMed Central. The manuscript management system is completely online and includes a very quick and fair peer-review system, which is all easy to use. Visit http://www. dovepress.com/testimonials.php to read real quotes from published authors.

\footnotetext{
Submit your manuscript here: http://www.dovepress.com/patient-preference-and-adherence-journal
} 